\title{
OS PROCEDIMENTOS ADOTADOS PELO TRIBUNAL DE CONTAS DO PIAUÍ PARA A VERIFICAÇÃO DAS RECEITAS E DESPESAS VINCULADAS À EDUCAÇÃO*
}

\author{
Nicholas Davies*
}

\begin{abstract}
RESUMO: O artigo analisa procedimentos do Tribunal de Contas (TC) do Piauí para a verificação da receita e despesa vinculada à educação, constatando a oscilação e pouca clareza e firmeza na definição destes procedimentos. Por exemplo, embora a Constituição Estadual previsse o percentual mínimo de 30\% em manutenção e desenvolvimento do ensino (MDE), o TC só passou a exigir este cumprimento a partir de uma resolução sua de 1998. Mesmo assim, admitiu que, no caso de Teresina e outros municípios, esta exigência viesse a ser cumprida gradualmente e só alcançasse os 30\% em 2002. Em 2004, no entanto, reduziu esta exigência para $25 \%$. Com relação à contabilização de receitas e despesas, os procedimentos também variaram. A Resolução n. 1.606, de 1998, por exemplo, não detalhou as receitas vinculadas à MDE. $\mathrm{Na}$ definição de despesas classificadas como MDE, o TC acrescentou alguns itens não previstos nos artigos 70 e 71 da LDB, confundindo gastos legalmente definidos como MDE com os classificados pela Lei do Orçamento Público.
\end{abstract}

Palavras-chave: Financiamento da educação. Receita e despesa em educação. Tribunal de Contas do Piauí.

* Este artigo é resultado de pesquisa apoiada pelo CNPq com bolsa de produtividade em pesquisa, desde março de 2007.

** Doutor em Sociologia e professor da Faculdade de Educação da Universidade Federal Fluminense (UFF). E-mail: nicholas@pq.cnpq.br 
Os procedimentos adotados pelo tribunal de contas do Piauí...

The procedures adopted by the Audit Office (ao) of the Brazilian State of Piauí to Check the revenues and eXPenditures LINKED TO EDUCATION

\begin{abstract}
This paper examines the procedures adopted by the Audit Office (AO) of the Brazilian State of Piauí to check the revenues and expenditures linked to education. It found that such procedures oscillate and are not very clearly and firmly defined. For example, although the State Constitution of Piauí stipulates that a minimum of $30 \%$ of tax revenue be earmarked to the legally-defined concept of maintenance and development of education (MDE), the AO only began to require it be enforced after a resolution issued in 1998. Yet, it allowed the capital city of Teresina and other townships to only gradually comply with it and reach $30 \%$ in the year of 2002. In 2004, however, the AO reduced this requirement to $25 \%$ (the minimum set by the Federal Constitution). As for the accounting of revenues and expenditures, procedures have also varied. Resolution 1.606 (1998), for example, does not detail the revenues linked to MDE. Regarding the expenses classified as MDE, the AO added some items not provided for in articles 70 and 71 of the Brazilian General Law on Education (LDB), thus confounding expenses legally defined as MDE with others classified as education in the Federal Budgetary Law.
\end{abstract}

Key words: Education funding. Revenues and expenses on education. Audit Office of the Brazilian State of Piauí.

\title{
Introdução
}

E ste artigo examina os procedimentos adotados pelo Tribunal de Contas do Estado do Piauí na verificação da aplicação dos recursos vinculados à educação, sendo parte de uma pesquisa sobre o papel dos Tribunais de Contas (TC) do Brasil nesta verificação. A pesquisa procurou obter as normas editadas pelos TC desde a Lei Federal n. 7.348, de 1985, que regulamentou a Emenda Constitucional Calmon, de 1983, restabelecendo a vinculação de recursos para a educação, eliminada pela Constituição imposta pela ditadura militar em 1967. Tomamos a Lei n. 7.348 como marco inicial, porque, desde 1967, não havia vinculação constitucional de recursos (restabelecida apenas para os municípios pela Emenda Constitucional n. 1, em 1969) e porque ela vigorou, integralmente, até dezembro de 1996 (quando foi promulgada 
a LDB) e, parcialmente, a partir de janeiro de 1997, segundo a interpretação dada pelo Parecer n. 26/97 do Conselho Nacional de Educação. Basicamente, esta Lei n. 7.348 foi importante porque definiu as receitas e despesas vinculadas à Manutenção e Desenvolvimento do Ensino (MDE), conceito que mereceu uma definição menos elástica do que a permitida pela função orçamentária de "Educação e Cultura", prevista na Lei Federal n. 4.320, de 1964, que normaliza a elaboração e execução de orçamentos públicos.

Outras referências legislativas que adotamos foram as Emendas Constitucionais n. 14, de setembro de 1996, e n. 53 (de dezembro de 2006), e as Leis n. 9.394, n. 9.424 (esta última regulamentou o FUNDEF), ambas de dezembro de 1996, e a n. 11.494 (que regulamentou o FUNDEB, criado pela EC-53). Basicamente, as informações e documentos que procuramos obter junto ao TC foram os seguintes:

1) Legislação federal, estadual ou municipal adotada pelo TC para a averiguação das receitas e despesas vinculadas à educação ou, mais precisamente, à MDE, conforme definida na Lei n. 7.348, de 1985, e nos artigos 70 e 71 da LDB. Queríamos saber, por exemplo, o percentual mínimo que os TC consideravam correto, no caso de o percentual das Constituiçóes estaduais e leis orgânicas ser superior aos $25 \%$ previstos na Constituição Federal (CF) de 1988.

2) Instruções e normas internas elaboradas pelo TC para o cálculo das receitas e despesas vinculadas à MDE desde a Lei n. 7.348. Tais instruções são fundamentais porque os governos estaduais e municipais procuram seguir (quando lhes interessam, é claro) os procedimentos nelas contidos, não necessariamente a Constituição Federal, Estadual ou Lei Orgânica ou a legislação educacional (LDB, por exemplo).

3) Definição dos impostos que compõem a base de cálculo do percentual mínimo. Queríamos saber, sobretudo, se era computada a receita da dívida ativa oriunda de impostos (DAI), sua atualização monetária e as multas e juros de mora sobre esta dívida.

4) Contabilização dos ganhos (quando a receita é maior do que a contribuição para o FUNDEF/FUNDEB), complementação federal e rendimentos financeiros com o FUNDEF/FUNDEB, receitas do 
Os procedimentos adotados pelo tribunal de contas do Piauí...

salário-educação, convênios de natureza educacional (merenda e outros) e receitas de serviços prestados por instituiçóes educacionais e operações de crédito para a educação. Queríamos saber se eram contabilizados como parte do percentual mínimo ou como acréscimos a ele. Este cálculo é importante porque, muitas vezes, os governos omitem tais receitas ou as incluem na base de cálculo do percentual mínimo, quando o correto é acrescentálas integralmente ao mínimo.

5) Critérios de cálculo do valor devido em educação: valores nominais ou valores reais, ou, em outras palavras, os valores devidos são corrigidos monetariamente? Estes critérios são fundamentais numa época de inflação alta e mesmo após a decretação do Plano Real, em julho de 1994, porque a inflação persistiu, embora relativamente baixa.

6) Definição de despesas consideradas como MDE. É fundamental a clareza sobre essa definição porque, não raro, os governos confundem tais despesas com as realizadas na função orçamentária "Educação e Cultura", modificada para "Educação" a partir de 2001, mais ampla do que o conceito de MDE, ou com o órgão responsável pela educação.

7) Critérios de cálculo das despesas em MDE - valores empenhados, liquidados ou pagos no ano. Essa diferenciação é fundamental porque não é incomum os governos considerarem os valores empenhados como os aplicados no ensino, mas cancelarem uma parte de tais empenhos no exercício seguinte, fraudando, assim, os valores aplicados no ensino.

8) Procedimentos adotados pelos TC, tendo em vista a implantação do Fundo de Manutenção e Desenvolvimento do Ensino Fundamental e de Valorização dos Profissionais do Magistério (FUndef), em 1998, e do Fundo de Manutenção e Desenvolvimento da Educação Básica e de Valorização dos Profissionais da Educação (FUNDEB), em 2007.

Análise das resoluçôes e documentos do TC do Piauí

O nosso estudo se baseou nos seguintes documentos do TC: Resoluções n. 831, de 19/3/98, n. 1.606 (avaliação de contas da educação e 
do FUNDEF), de $18 / 6 / 98$, n. 3.451 (permite o cumprimento dos $30 \%$ do percentual mínimo de municípios só em 2002), de 2/12/99, n. 1.194 , de 23/10/02 (suprime a exclusão de inativos no cômputo dos gastos em educação), n. 315, de 20/3/04, 1.276 (avaliação de contas municipais e do FUNDEF) e n. 1.277 (avaliação de contas estaduais e do FUNDEF), ambas de 16/12/04, n. 1.604 (avaliação de contas estaduais, do ensino e do FUNDEB) e n. 1.605 (avaliação de contas municipais, do ensino e do FUNDEB), de 13/12/07, relatórios do TC sobre as contas estaduais de 1998 e 2002 e sobre as contas dos municípios de Água Branca (2000) e Lagoa do Piauí (2001), bem como em respostas de órgãos do TC a questionamentos por nós dirigidos a ele em janeiro de 2005 e maio de 2008.

É interessante observar que algumas resoluçōes (a n. 1.606, por exemplo) do TC contêm vários artigos idênticos (até em erro de português!) à Resolução n. 354, de 1998, do TC dos municípios da Bahia. Cabe lembrar que a nossa análise é prejudicada, pelo menos parcialmente, pelo fato de a página do TC (www.tce.pi.gov.br) não conter relatórios das receitas e gastos em MDE dos governos, mas apenas estas resoluções, que não são necessariamente seguidas pelos TC, conforme pudemos constatar na análise de outros Tribunais.

\section{O percentual mínimo vinculado à educação}

O primeiro ponto que chama atenção nos procedimentos do TC é que, até 1998, ele parece ter se baseado no percentual de $25 \%$, mesmo quando a Constituição Estadual (CE) fixava 30\% como mínimo. Ou seja, de 1990 (primeiro ano após a promulgação da CE) a 1998, o TC não cobrou a aplicação de $5 \%$ (a diferença entre os $30 \%$ e os $25 \%$ ) dos impostos na educação. O prejuízo também aconteceu nos municípios, pois a CE fixou o mesmo percentual para eles.

A partir de 1999, o TC, segundo a Resolução n. 831, de março de 1998, passaria a exigir a aplicação de 30\% tanto do Estado quanto dos municípios. Os motivos para esta mudança de procedimento parecem ser a explicitação, no caput do artigo 69 da LDB, de que os percentuais mínimos são os fixados nas CE e leis orgânicas, pois o preâmbulo da Resolução n. 831 considera que tal artigo 69 "encerrou definitivamente qualquer dúvida porventura existente quanto à eficácia da disposição contida no artigo 223 da Constituição Estadual" (o qual fixa 
Os procedimentos adotados pelo tribunal de contas do Piauí...

o mínimo de 30\%) e que a CF "faculta que as Constituições Estaduais e Leis Orgânicas municipais, segundo as carências e peculiaridades de cada Estado e Município, optem por percentuais superiores." Já com a Resolução n. 3.451, de 2/12/99, atendendo à consulta feita pela prefeitura de Teresina e pela Associação Piauiense de Municípios, o TC flexibilizou tal exigência ao permitir que municípios cumprissem o percentual de modo progressivo, ano a ano, a partir de 1999, alcançando os 30\% somente em 2002. Aparentemente, a exigência dos $30 \%$ ficou apenas no papel, pois os relatórios do TC sobre as contas de 2002 do governo estadual (Piauí, TCE, 2003) e também sobre as contas municipais de Água Branca e Lagoa do Piauí, respectivamente, em 2000 e 2001, só mencionam os $25 \%$. Embora o percentual aplicado em Lagoa do Piauí tenha sido, segundo o TC, bem superior aos $30 \%$ (44\%), os relatórios do TC fazem referência apenas aos 25\% fixados pela CF. Em 2004, através das resoluçóes n. 1.277 (para o Estado) e n. 1.276 (para os municípios), o TC reduziu o percentual mínimo para $25 \%$, sem nenhuma justificativa. Solicitamos esclarecimentos sobre este e outros pontos ao $\mathrm{TC}^{1}$ e as suas respostas e os nossos comentários são apresentados a seguir.

Várias instâncias do TC se manifestaram sobre as nossas indagações e questionamentos. Uma foi a IV Divisão da Diretoria de Fiscalização da Administração Estadual (DFAE), que, alegando a falta de consenso entre os TC, justificava não reprovar contas de governos que aplicassem mais do que $25 \%$ e menos do que $30 \%$. A v Divisão Técnica da Diretoria de Fiscalização da Administração Municipal (DFAM), por sua vez, informou, sem nenhuma justificativa para esta alegação, ser "questionável reprovar contas de gestores que haviam aplicado entre 25\% e 30\%". O auditor fiscal Jackson Nobre Veras, em ofício de 19/12/06, afirmou que, "desde a apreciação das contas do Governo Estadual referente ao exercício de 2000 firmou-se o entendimento de que a Constituição Estadual não poderia fixar um percentual superior àquele estabelecido pela Constituição Federal". Em defesa do percentual de 25\%, citou decisão do Supremo Tribunal Federal (STF) que, ao apreciar a Ação Direta de Inconstitucionalidade (ADIN 780-7), movida pelo então governador Leonel Brizola, do Rio de Janeiro, teria declarado inconstitucional dispositivo da CE que eleve o percentual mínimo acima dos 25\% "por afrontar o princípio da separação dos poderes". Segundo o STF, somente o Executivo poderia fixar percentual superior 
através de lei de sua iniciativa. A comunicação interna n. 1/08, de 1/7/ 2008, da DFAE/DFAM, repete as mesmas alegações e uma nova: a de que o percentual superior a $25 \%$ seria inconstitucional.

As alegaçōes do TC são bastante frágeis, por várias razões. Uma é que o TC não tem competência para julgar a constitucionalidade da legislação. Outra é que não é uma decisão, mas sim uma liminar do STF, ou seja, este não decidiu quanto ao mérito da ADIN. Outra razão é que a ADIN se refere à Constituição Estadual do Rio de Janeiro, não à do Piauí, e por isso ela só se aplica ao estado do Rio de Janeiro. Uma quarta razão é que o Legislativo tem ou pelo menos deveria ter autonomia para elaborar as leis, inclusive a $\mathrm{CE}$, sem se submeter ao Executivo. Portanto, se o Legislativo fixou um percentual mínimo superior aos $25 \%$, estava no seu direito de assim fazê-lo. Uma quinta razão é que o Legislativo só estaria infringindo a $\mathrm{CF}$ se estipulasse um percentual inferior a $25 \%$. Isso sim seria uma inconstitucionalidade. A fixação de um percentual superior aos $25 \%$ é uma prerrogativa do Legislativo, para atender as particularidades de estados e municípios.

Provavelmente, para facilitar o cumprimento do percentual mínimo pelo governo estadual, que não vinha aplicando os $30 \%$ em educação, os deputados modificaram, com a Emenda n. 13, em 21/12/ 2000 , o artigo que prevê os $30 \%$ para MDE, de modo a permitir até $5 \%$ (dos 30\%) serem gastos em capacitação, requalificação profissional e de mão-de-obra, atividades legalmente não classificadas como MDE, embora tenham caráter genericamente educacional. Ou seja, na prática, o percentual mínimo foi reduzido de $30 \%$ para $25 \%$, embora o artigo 223 da CE continue vinculando $30 \%$ à $\mathrm{MDE}$, que não abrange tal capacitação. É possível que esta "\$en\$ibilidade" dos deputados seja uma resposta às Resoluçôes n. 831 e n. 1.606, que determinavam expressamente a aplicação dos $30 \%$ em MDE. De qualquer maneira, as resoluções do TC não parecem ter importância para o governo estadual, que nas contas de 1999 a 2007 (ver <http://www.sefaz.pi.gov.br/ conteudo_internet.php?p=rd_balancos $>$ ) só tomou como referência os $25 \%$, nunca os $30 \%$.

\section{Os componentes da receita vinculada à educação}

Ao contrário da Resolução n. 831, que se ocupou apenas da definição do percentual mínimo, a n. 1.606, com 23 artigos e dois anexos, 
Os procedimentos adotados pelo tribunal de contas do Piauí...

procurou fixar critérios de cálculo das receitas e despesas em MDE e FUNDEF. Incluiu a dívida ativa de impostos na base de cálculo e explicitou ( $\$$ único do art. $6^{\circ}$ ) corretamente que salário-educação, convênios, subvenções e programas específicos não comporão a base de cálculo do percentual mínimo. Este procedimento correto continuou em todas as resoluções posteriores. A questão é saber se o TC seguiu tal procedimento em suas análises concretas. No seu relatório sobre as contas estaduais de 1998 (Piauí, TCE, 1999), por exemplo, equivocou-se ao não mencionar a dívida ativa de impostos e incluir a complementação federal ( $\mathrm{R} \$ 8,5$ milhões) para o FUNDEF na base de cálculo, embora tenha excluído corretamente os R \$,2 milhôes do salário-educação, divergindo da prestação de contas do governo estadual, que havia incluído o salário-educação no cálculo do percentual mínimo.

A propósito do salário-educação, as Resoluções n. 1.277, de 2004, e n. 1.604, de 2007, cometeram dois equívocos. Um, comum às duas, foi dar a entender que é uma receita apenas do governo estadual, quando, desde 2004, em virtude da Lei federal n. 10.832, de dezembro de 2003, as prefeituras passaram a receber, diretamente do Fundo Nacional de Desenvolvimento da Educação (FNDE), uma cota proporcional ao número de matrículas municipais no ensino fundamental e, desde 2007, na educação básica. Ou seja, de 2004 a 2006, a cota estadual passou a ser repartida entre o governo estadual e as prefeituras, com base no número de matrículas no ensino fundamental (regular e educação de jovens e adultos). O segundo equívoco, cometido apenas pela Resolução n. 1.604, foi estipular que o salário-educação é destinado a financiar o ensino fundamental, quando, desde 2007, em função da Emenda Constitucional n. 53 (que criou o FUNDEB), ele é destinado a toda a educação básica, não mais apenas ao ensino fundamental. Em resposta ao meu pedido de informações e esclarecimentos protocolado no TC em 27/5/08 sob n. 019632/08, o TC alegou já ter identificado estes dois equívocos, através da Comunicação Interna n. 001/08 (Piauí, TCE, 2008). Porém, não providenciou a sua alteração até setembro de 2008.

Apesar de muita detalhada, a Resolução n. 1.606 apresentava falhas. O seu Anexo II (demonstrativo financeiro trimestral/MDE) não previu a especificação dessa receita adicional (salário-educação, convênios, ganho e complementação federal com o FUNDEF etc.), o que podia levar a cálculos equivocados. Por exemplo, a complementação federal, 
de mais de R\$ 9 milhões para o governo estadual em 2002, foi, assim como em 1998, contabilizada dentro dos $25 \%$, quando deveria ter sido acrescentada ao percentual mínimo, de 30\%. Tal contabilização equivocada da complementação foi também cometida pelo governo em todas as contas estaduais durante a vigência do FUNDEF (1998 a 2006) e no primeiro ano do FUNDEB (2007).

$\mathrm{O}$ anexo equivocou-se também ao indicar rubricas nas quais, segundo o artigo $11 \mathrm{da} \mathrm{LDB}$, prefeituras não podem aplicar a receita vinculada, como o ensino médio e o ensino superior, enquanto não atenderem satisfatoriamente a educação infantil e o ensino fundamental. Além disso, o anexo não menciona o governo estadual, cujas receitas são diferentes das municipais. As deficiências e insuficiências dos anexos só vieram a ser sanadas mais de seis anos depois, em dezembro de 2004, com as Resoluçôes n.1.276 e n. 1.277, cujos anexos seguem os modelos contidos no Manual do Relatório Resumido da Execução Orçamentária, editado pela Secretaria do Tesouro Nacional (Brasil, Ministério da Fazenda, 2003).

Entretanto, os anexos, apesar de bastante exatos, omitiram o rendimento financeiro com as receitas do FUNDEF, previsto na Lei n. 9.424. A Resolução n. 1.605 (relativa às contas municipais), de 2007, por sua vez, cópia das tabelas do Manual do Relatório Resumido da Execução Orçamentária editado pela Secretaria do Tesouro Nacional em 2007 (Brasil, Ministério da Fazenda, 2007), é bastante detalhada e exata para o cálculo das receitas e despesas em MDE. A Resolução n. 1.604 (relativa às contas estaduais), no entanto, não contém tais tabelas e a explicação pouco convincente dada pelo TC foi de que isso foi "uma opção para reduzir o número de anexos" (Piauí, TCE, 2008). A descrição das receitas do FUNDEB no texto de ambas as resoluções (n. 1.604 e n. 1.605) é imprecisa e incongruente. Referem-se à composição do FUNDEB, quando, no caso da n. 1.605, o certo é "contribuição" (os impostos dos municípios que formam o FUNDEB: o ICMS, o FPM, o IPI-exportação, o IPVA, o ITR, a desoneração do ICMS das exportações). Já a n. 1.604 equivocou-se no emprego do termo "composição", quando quis dizer "receita" total em âmbito estadual, ou seja, do governo estadual e de todos os municípios do Estado. De qualquer maneira, o correto seria a n. 1.604 informar a contribuiçãao prevista do governo estadual para o FUNDEB, não a receita total em âmbito estadual, que não é o mesmo que receita do governo estadual. 
Os procedimentos adotados pelo tribunal de contas do Piauí...

\section{As despesas em $M D E$}

$\mathrm{Na}$ definição dessas despesas, a Resolução n. 1.606 confundiu, no seu anexo II (demonstrativo financeiro trimestral/ MDE), MDE (definida pela LDB) com Educação e Cultura (função orçamentária definida pela Lei n. 4.320, do orçamento público). Ora, nem toda despesa da função Educação e Cultura (alterada posteriormente para a função Educação) pode ser classificada como MDE. Um exemplo é a merenda escolar, não classificável como MDE. Além disso, a resolução reproduziu os artigos 70 e 71 da LDB, porém tomou a liberdade de reformular ou acrescentar alguns incisos, às vezes contraditórios entre si. Por exemplo, o inciso $\mathrm{V}$ do seu artigo $3^{\circ}$ reproduziu o mesmo inciso do artigo 70 e acrescentou que, entre as atividades-meio necessárias ao funcionamento dos sistemas de ensino, se incluem "aquelas desempenhadas por pessoal de apoio administrativo, vigilantes, zeladores, motoristas de transporte vinculado ao ensino, bibliotecários, jardineiros e secretários de escola", entrando em contradição com o inciso III do artigo $4^{\circ}$, segundo o qual "a contratação ou pagamento de milícias que auxiliem na segurança dos estabelecimentos educacionais" não será considerada MDE (grifos nossos). Ora, a função de vigilantes parece a mesma de milícias e as disposiçôes destes incisos são nitidamente contraditórias. Outro acréscimo está no inciso VIII do artigo $3^{\circ}$, que inclui os professores entre os beneficiáveis com o transporte escolar, disposição não contida no artigo 70 da LDB e em contradição com as recomendações da Carta dos Técnicos do MEC e dos Tribunais de Contas do Brasil (1999). Tais acréscimos continuaram nas resoluçốes n. 1.276 e n. 1.277, de 2004, e n. 1.604 e n. 1.605 , de 2007.

Outro equívoco da Resolução n. 1.606 foi considerar como MDE os recursos destinados a escolas comunitárias, confessionais ou filantrópicas, desde que atendessem às condições previstas no artigo 77 , incisos I a IV da LDB (inciso VII do artigo $3^{\circ}$ da Resolução). É um equívoco porque, embora tais escolas possam receber recursos públicos, estes não podem ser classificados como MDE, conforme consta da LDB. Esta é mais uma contradição do TC, que alegou seguir a legislação federal para o percentual mínimo, porém tomou a liberdade de modificar a LDB na definição de MDE. O que é mais grave, permitiu, na Resolução n. 1.606, que recursos destinados a tais escolas fossem contabilizados dentro dos $40 \%$ do FUNDEF (parágrafo único do artigo 13), o qual se destinava 
exclusivamente ao ensino fundamental público e, portanto, não poderia beneficiar tais escolas não-públicas. Estes equívocos continuaram nas Resoluções n. 1.276 (de avaliação de contas municipais) e n. 1.277 (de avaliação de contas estaduais), ambas de 16/12/04. Em resposta ao nosso questionamento, a V Divisão Técnica da DFAM do TCE limitou-se a repetir o previsto nas resoluçóes, sem apresentar argumento novo. As resoluções seguintes, a n. 1.604 (para contas estaduais e o FUNDEB estadual) e a n. 1.605 (para contas municipais e o FUNDEB municipal), ambas de 13/12/07, são contraditórias entre si. Enquanto a n. 1.604 mantém o equívoco das resoluções anteriores, a n. 1.605 é omissa nesta questão e se limita a considerar ou não como MDE o que consta dos artigos 70 e 71 da LDB. Em resposta às nossas indagações em maio de 2008, o TCE alegou já ter identificado esse problema e que estaria providenciando a alteração da Resolução n. 1.604 (Piauí, TCE, 2008), alteração não providenciada até setembro de 2008.

O TC oscilou também na interpretação sobre o emprego do FUNDEF em bolsas de estudo em escolas públicas e privadas, não previsto na lei deste Fundo (a n. 9.424, de dezembro de 1996). O equívoco desta interpretação está no fato de o FUNDEF ter se destinado apenas ao ensino fundamental público e, portanto, não poderia ser empregado em escolas privadas. $\mathrm{O}$ equívoco do TC foi confundir despesas em MDE (definidas nos artigos 70 e $71 \mathrm{da}$ LDB), que incluem bolsas de estudo em escolas privadas, com despesas no FUNDEF, que só podiam ser no ensino fundamental público. As Resoluções n. 1.606, 1.276 e 1.277 cometeram este equívoco, corrigido, no caso dos recursos do FUNDEB, pelas Resoluções n. 1.604 e 1.605, que não permitem o emprego dos recursos do FUNDEB em tais bolsas. A n. 1.604 (avaliação de contas estaduais), no entanto, equivocou-se ao classificar as despesas de MDE (artigo 29) apenas as financiadas com o FUNDEB, omitindo as demais receitas estaduais de impostos que não integram o FUNDEB, a saber, os 25\% do IR dos servidores estaduais e os $5 \%$ de todos os outros impostos, se tomarmos como referência apenas os $25 \%$ adotados pelo TC. O estranho nesta classificação equivocada é que a n. 1.604 contém duas definições de MDE, uma em geral (embora tendo como referência apenas os recursos do FUNDEB) e outra específica do FUNDEB. Na definição geral (artigo 29), as bolsas de estudo são correta e legalmente consideradas como MDE, porém não na definição específica (artigo 35). Em resposta ao nosso questionamento, o TC alegou já ter identificado este problema e 
Os procedimentos adotados pelo tribunal de contas do Piauí...

que estaria providenciando tal alteração (Piauí, TCE, 2008), o que não foi feito até setembro de 2008.

$\mathrm{Na}$ definição de despesas que não são de MDE, além de reproduzir o artigo 71 da LDB, a Resolução n. 1.606 excluiu explicitamente os proventos de inativos, a desapropriação de áreas de acesso às escolas e gastos em rádio e TV educativa, construção de bibliotecas, museus e quadra poliesportiva não vinculados a unidades educacionais. Entretanto, em resolução posterior, a n. 1.194 , de 23/10/02, a exclusão dos proventos de inativos foi omitida, o que pode significar que o TC passou a aceitar tais proventos como despesas de MDE. Isso aconteceu pelo menos na sua apreciação das contas estaduais de 2002. A questão é saber se a Resolução n. 1.194 , de outubro de 2002, pode ter vigência retroativa a janeiro de 2002. Em 2004, através das Resoluçôes n. 1.276 e 1.277, o TC voltou a excluir expressamente os proventos. Entretanto, em dezembro de 2007, a Resolução n. 1.605 (avaliação de contas municipais) foi omissa nesta questão, embora a n. 1.604 (avaliação de contas estaduais) excluísse os proventos de MDE. De qualquer modo, a oscilação do TC demonstra a sua pouca firmeza e clareza sobre a matéria.

Com relação à definição de despesas válidas (empenhadas, liquidadas ou pagas) para fins de comprovação da aplicação do percentual mínimo, a n. 1.606 se baseou em despesas pagas, aceitando, no entanto, as empenhadas não pagas, se "comprovado saldo financeiro reservado a esse pagamento" (parágrafo único do artigo $4^{\circ}$ ). Isso, no entanto, parece contradizer o $\$ 1^{\circ}$ do artigo $3^{\circ}$, segundo o qual os restos a pagar somente serão considerados como aplicação em MDE no exercício e no montante em que forem efetivamente pagos, confundindo despesas de exercícios diferentes. Tal interpretação continuou nas Resoluções n. 1.276 e 1.277, de 2004, e 1.604 e 1.605 , de 2007.

Por fim, a n. 1.606 equivocou-se ao permitir que parte dos $60 \%$ (percentual fixado na Lei n. 9.424) destinados à remuneração dos profissionais do magistério no ensino fundamental fosse usada na qualificação de professores leigos, quando o certo é "habilitação", diferente de "qualificação". Afinal, qualquer curso de qualquer duração qualifica, mas nem todo curso habilita o professor leigo. O curso que o faz tem uma carga horária mínima definida legalmente. Esta distinção fica clara no artigo $9^{\circ}$ da Lei n. 9.424, que regulamentou o FUNDEF. A Resolução n. 1.604, por sua vez, se equivocou na redação no $\$ 6^{\circ}$ do artigo 35 , que prevê "a aplicação dos $60 \%$ dos profissionais da educação", 
quando o certo é "a aplicação de pelo menos 60\% do FUNDEB na remuneração dos profissionais do magistério da educação básica”. Questionado em nosso ofício de maio de 2008, o TC não esclareceu este ponto.

A n. 1.606 também fez uma exigência (artigo 19, $\$ 1^{\circ}$ ) pouco comum em TC, que é a de os governos apresentarem um demonstrativo trimestral da aplicação do percentual mínimo. Como nem a Resolução, nem o Anexo II estipulam a natureza dos valores (empenhados, liquidados ou pagos), a exigência pode ter sido facilmente contornada por meio do lançamento de empenhos e não dos valores efetivamente pagos. Esta deficiência foi sanada pelas resoluções posteriores, de 2004 (a n. 1.276 e a 1.277) e 2007 (a n. 1.604 e a 1.605 ).

\section{Conclusões}

O exame das resoluções do TC de 1998 a 2007 e de seus relatórios sobre contas estaduais de 1998 e 2002 permite as seguintes conclusões: uma é a oscilação e, portanto, pouca clareza e firmeza do TC. Embora a CE de 1989 previsse o percentual mínimo de 30\% em MDE, ele só passou a exigir este cumprimento a partir de uma resolução sua de 1998. Mesmo assim, admitiu que, no caso de Teresina e outros municípios, esta exigência só viesse a ser cumprida gradualmente e só alcançasse os 30\% em 2002. Em 2004, no entanto, reduziu esta exigência para 25\%. Questionado, o TC respondeu com alegações vagas e bastante frágeis. Ou seja, os governos estadual e municipais puderam e podem descumprir a exigência dos $30 \%$, porque o TC aceitou e aceita tal descumprimento. Com relação à contabilização de receitas e despesas, os procedimentos do TC também variaram desde 1998 até 2007. A Resolução n. 1.606, de 1998, por exemplo, não era muito detalhada na definição das receitas, levando a equívocos como a inclusão da complementação federal dentro do percentual mínimo pelo governo estadual e também pelo TC. Esta pormenorização insuficiente só veio a ser sanada em 2004, com as Resoluções n. 1.276 e 1.277, certamente porque se limitaram a copiar os modelos fornecidos pelo Manual de Relatório Resumido da Execução Orçamentária, publicado pela Secretaria do Tesouro Nacional para orientar a prestação de contas bimestral dos governos. Ou seja, não foi mérito do TC. Na definição de despesas aceitas como MDE, o TC tomou a liberdade de acrescentar algumas não previstas nos artigos 70 e $71 \mathrm{da}$ LDB, confundindo despesas em MDE 
Os procedimentos adotados pelo tribunal de contas do Piauí...

com as da função orçamentária "Educação". Por exemplo, permitiu equivocadamente que recursos públicos destinados a escolas comunitárias, confessionais ou filantrópicas fossem contabilizados dentro do percentual mínimo e também dentro dos $40 \%$ do FUNDEF, um grave equívoco, porque este Fundo era reservado exclusivamente ao ensino fundamental público. A fragilidade do TC nesta questão fica evidente porque suas resoluçóes mais recentes, a n. 1.604 e a n. 1.605, de dezembro de 2007, não prevêem o uso de recursos do FUNDEB em tais escolas, embora a n. 1.604 (a n. 1.605 é omissa nesta questão) permita que recursos fora do FUNDEB destinados a tais escolas sejam classificados como MDE. Outro exemplo da oscilação do TC é a classificação dos inativos em MDE, ora excluídos de MDE (Resolução n. 1.606), ora aceitos como MDE (resolução de outubro de 2002), ora excluídos novamente (resoluções de dezembro de 2004 e Resolução n. 1.604, de dezembro de 2007), ora omitidos (Resolução n. 1605, de dezembro de 2007). Por fim, é fundamental saber se e como o TC cumpre as suas resoluções na apreciação das contas dos governos, pois os seus relatórios sobre as contas estaduais de 1998 e 2002 mostram exemplos de descumprimento destas resoluções (como o percentual mínimo de 30\%).

\section{Recebido em dezembro de 2008 e aprovado em novembro de 2009.}

\section{Nota}

1. Feita por requerimento protocolado pelas professoras Rosana Evangelista da Cruz e Maria do Socorro Lages de Carvalho, do Núcleo de Estudos e Pesquisas em Políticas e Gestão da Educação, da Universidade Federal do Piauí, a quem agradeço pelo fornecimento de vários documentos e informações que possibilitaram este estudo. Agradeço também a Samara de Oliveira Silva, que, em 27/5/2008, protocolou outro pedido de informações, sob o n. 019632/08.

\section{Referências}

BRANCO, A.N.L.C. (presidente do TCE/PI). Ofício 156/07, de 19/ 01/07. Teresina, 2007. Acompanham o ofício do auditor fiscal Jackson Veras a comunicação interna n. 6, da IV DFAE (Divisão de Fiscalização da Administração Estadual) e a comunicação interna n. 1, da V DFAM (Diretoria de Fiscalização da Administração Municipal), 
que respondem ao pedido de informações protocolado pela professora Rosana Evangelista de Souza.

BRANCO, A.N.L.C. (presidente do TCE/PI). Ofício 6.248/08, de 30/ 06/08. Teresina, 2008. Acompanha a comunicação interna n. 1/08, de 1/07/08, da DFAE/DFAM, que responde ao pedido de informações e esclarecimentos protocolado em 27/05/08 sob n. 019632.

BRASIL. Constituição (1988). Constituição da República Federativa do Brasil. Brasília, DF: Senado Federal, 2002. Disponível em: <http:// www.senado.gov.br>. Acesso em: fev. 2008.

BRASIL. Emenda Constitucional n. 14, de 12 de setembro de 1996. Modifica os artigos 34, 208, 211 e 212 da CF e dá nova redação ao artigo 60 do ADCT (cria o FUNDEF). Diário Oficial da União, Brasília, DF, 13/09/96. Disponível em: <http://www.planalto.gov.br>. Acesso em: out. 2005.

BRASIL. Emenda Constitucional n. 53, de 19 de dezembro de 2006. Dá nova redação aos artigos 7o, 23, 30, 206, 208, 211 e 212 da Constituição Federal e ao artigo 60 do Ato das Disposiçōes Constitucionais Transitórias. Diário Oficial da União, Brasília, DF, 20/12/2006. Disponível em: <http://www.planalto.gov.br>. Acesso em: jan. 2007.

BRASIL. Lei 7.348, de 24 de julho de 1985. Regulamenta a Emenda Constitucional n. 24, de dezembro de 1983. Diário Oficial da União, Brasília, DF: 25/07/1985. Disponível em: <http://www.planalto.gov.br>. Acesso em: out. 2005.

BRASIL. Lei n. 9.394, de 20 de dezembro de 1996. Estabelece as diretrizes e bases da educação nacional. Diário Oficial da União, Brasília, DF, 23/12/1996. Presidência da República. Disponível em: <http://www.planalto.gov.br>. Acesso em: out. 2005.

BRASIL. Lei 9.424, de 24 de dezembro de 1996. Dispõe sobre o FUNDEF e dá outras providências. Diário Oficial da União, Brasília, DF, 26/12/1996. Disponível em: <http://www.planalto.gov.br>. Acesso em: out. 2005.

BRASIL. Lei n. 11.494, de 20 de junho de 2007. Conversão da Medida Provisória n. 339, de 2006. Regulamenta o Fundeb, altera a Lei 
Os procedimentos adotados pelo tribunal de contas do Piauí...

n. 10.195 , de 14/2/01, revoga dispositivos das Leis n. 9.424, de 24/ $12 / 96,10.880$, de $9 / 6 / 04$, e 10.845 , de $5 / 3 / 04$, e dá outras providências. Diário Oficial da União, Brasília, DF, 21/06/2007. Disponível em: <http://www.planalto.gov.br>. Acesso em: jul. 2007.

BRASIL. Ministério da Educação. Conselho Nacional de Educação. Parecer n. CP 26/97, de 2 de dezembro de 1997. Interpreta o financiamento da educação na LDB. Brasília, DF, 1997. Disponível em: <http://www.mec.gov.br>. Acesso em: jun. 1998.

BRASIL. Ministério da Fazenda. Secretaria do Tesouro Nacional. Anexo de metas fiscais e relatório resumido da execução orçamentária: manual de elaboração aplicado à União e aos Estados, Distrito Federal e Municípios. 7. ed. atual. Brasília, DF: Secretaria do Tesouro Nacional, Coordenação-Geral de Contabilidade, 2007.

BRASIL. Ministério da Fazenda. Secretaria do Tesouro Nacional. Coordenação Geral de Contabilidade. Relatório resumido da execução orçamentária: manual de elaboração. 3. ed. Brasília, DF: STN, 2003.

CARTA dos técnicos do Ministério da Educação e dos Tribunais de Contas sobre o FUNDEF. Brasília, DF, 1o jul. 1999. 32p.

CARVALHO, M.S.L. Processo de implantação e o impacto do FUndef em Teresina, Piauí. In: Luz, L.X. (Org.). Gestão, financiamento e controle social da educação. Teresina: EDUFPI, 2005.

DAVIES, N. O FUNDEF e o orçamento da educação. Campinas: Autores Associados, 1999a.

DAVIES, N. Tribunal de Contas: faz as contas ou "faz de conta" na avaliação dos gastos governamentais em educação. Revista Brasileira de Estudos Pedagógicos, Brasília, DF, v. 80, n. 194, p. 19-27, jan./abr. $1999 \mathrm{~b}$.

DAVIES, N. Verbas da educação: o legal x o real. Niterói: EDUFF, 2000.

DAVIES, N. Tribunais de Contas e educação: quem controla o fiscalizador dos recursos? Brasília, DF: Plano, 2001.

DAVIES, N. Financiamento da educação: novos ou velhos desafios? São Paulo: Xamã. 2004a. 
DAVIES, N. Legislação educacional federal básica. São Paulo: Cortez, 2004b.

DAVIES, N. FUNDEB: a redenção da educação básica? Campinas: Autores Associados, 2008.

MELCHIOR, J.C.A. Mudanças no financiamento da educação no Brasil. Campinas: Autores Associados, 1997.

PIAUÍ. Assembléia Legislativa. Constituição Estadual de 1989. Emenda Constitucional Estadual n. 13, de 21/12/00. Diário da Assembléia, Teresina, edição especial de 25/1/01. Disponível em: <http/ /www.tce.pi.gov.br>. Acesso em: fev. 2008.

PIAUÍ. Secretaria Estadual de Fazenda. Balanços de 1999 a 2007. Disponível em: <http://www.sefaz.pi.gov.br/conteudo_internet.php? p=rd_balancos $>$. Acesso em: maio 2008.

PIAUÍ. Tribunal de Contas do Estado. Relatório Analitico das Contas do Governador do Estado do Piauí: exercício/98. Teresina: TCE, 1999.

PIAUÍ. Tribunal de Contas do Estado. Relatório Analítico das Contas do Governador do Estado do Piauí: exercício/2002. Teresina: TCE, 2003.

PIAUÍ. Tribunal de Contas do Estado. Relatório do Conselheiro-Relator Antonio de Barros Araújo sobre as contas de 1998 do governador. Teresina: TCE, 2000.

PIAUÍ. Tribunal de Contas do Estado. Relatório sobre as contas de 2000 de Água Branca. Teresina: TCE, 2001.

PIAUÍ. Tribunal de Contas do Estado. Relatório sobre as contas de 2001 de Lagoa do Piauí. Teresina: TCE, 2003.

PIAUÍ. Tribunal de Contas do Estado. Resolução n. 831, de 19/3/ 1998. Dispõe sobre a aplicação pelo Estado e Municípios, anualmente, do mínimo de trinta por cento de sua receita na manutenção e desenvolvimento do ensino. Teresina: TCE, 1998. Disponível em: <http://www.tce.pi.gov.br>. Acesso em: jan. 2008.

PIAUÍ. Tribunal de Contas do Estado. Resolução n. 1.606, de 18/6/ 1998. Dispõe sobre a fiscalização exercida pelo Tribunal de Contas 
Os procedimentos adotados pelo tribunal de contas do Piauí...

do Estado sobre a aplicação dos recursos constitucionalmente vinculados à manutenção e desenvolvimento do ensino no estado do Piauí. Teresina: TCE, 1998. Disponível em: <http://www.tce.pi.gov.br>. Acesso em: jan. 2008.

PIAUÍ. Tribunal de Contas do Estado. Resolução 3.451, de 2/12/ 1999. Resposta favorável à consulta pela prefeitura de Teresina e pela Associação Piauiense de Municípios sobre a possibilidade de só cumprir o percentual mínimo em 2002 e aplicar percentuais crescentes entre 1999 e 2002. Teresina: TCE, 1999.

PIAUÍ. Tribunal de Contas do Estado. Resolução n. 1.194, de 23/10/ 2002. Teresina: TCE, 2002.

PIAUÍ. Tribunal de Contas do Estado. Resolução n. 315, de 20/03/2004. Altera as Resoluções TCE n. 1.606, de 18/698, 1.451, de 11/12/03, 1.452 , de $11 / 12 / 03,1.454$, de $11 / 1203$, e 1.455 , de $11 / 1203$. Teresina: TCE, 2004. Disponível em: <http://www.tce.pi.gov.br>. Acesso em: jan. 2008.

PIAUÍ. Tribunal de Contas do Estado. Resolução n. 1.276, de 16/12/ 2004. Dispõe sobre a forma e prazo de prestação de contas da administração pública municipal direta e indireta ao Tribunal de Contas do Estado e dá outras providências. Teresina: TCE, 2004. Disponível em: <http://www.tce.pi.gov.br>. Acesso em: jan. 2008.

PIAUÍ. Tribunal de Contas do Estado. Resolução n. 1.277, de 16/12/ 2004. Dispõe sobre a forma e prazo de prestação de contas ao Tribunal de Contas pelos órgãos e entidades dos poderes Legislativo, Executivo, Judiciário do Estado e Ministério Público e dá outras providências. Teresina: TCE, 2004. Disponível em: <http://www.tce.pi.gov.br>. Acesso em: jan. 2008.

PIAUÍ. Tribunal de Contas do Estado. Resolução n. 1.604, de 13/12/ 2007. Dispõe sobre a forma e prazo de prestação de contas ao Tribunal de Contas pelos órgãos e entidades dos poderes Legislativo, Executivo, Judiciário do Estado e Ministério Público e dá outras providências. Teresina: TCE, 2007. Disponível em: <http://www.tce.pi.gov.br>. Acesso em: jan. 2008. [Dispõe sobre os recursos estaduais vinculados ao ensino e o FUNDEB]. 
PIAUÍ. Tribunal de Contas do Estado. Resolução n. 1.605, de 13/12/ 2007. Dispõe sobre a forma e prazo de prestação de contas da administração pública municipal direta e indireta ao Tribunal de Contas do Estado e dá outras providências. Teresina: TCE, 2007. Disponível em: <http://www.tce.pi.gov.br>. Acesso em: jan. 2008. [Dispõe sobre os recursos municipais vinculados ao ensino e o FUNDEB].

VELLOSO, J. A nova Lei de Diretrizes e Bases da Educação e o financiamento do ensino: pontos de partida. Educação \& Sociedade, Campinas, v. 10, n. 30, p. 5-42, ago. 1988.

VERAS, J.N. (auditor fiscal do TCE). Ofício datado de 19/12/06. Teresina: TCE, 2006. 